\title{
Multiplex networks reveal geographic constraints on illicit wildlife trafficking
}

\author{
Felber J. Arroyave ${ }^{1,2^{*}}$, Alexander M. Petersen ${ }^{3^{*}}$, Jeffrey Jenkins ${ }^{1,3}$ and Rafael Hurtado ${ }^{2}$
}

\author{
* Correspondence: fjarroyaveb@ \\ unal.edu.co; apetersen3@ucmerced. \\ edu \\ ${ }^{1}$ Environmental Systems, School of \\ Engineering, University of California, \\ Merced, CA 95343, USA \\ ${ }^{3}$ Management of Complex Systems \\ Department, Ernest and Julio Gallo \\ Management Program, School of \\ Engineering, University of California, \\ Merced, CA 95343, USA \\ Full list of author information is \\ available at the end of the article
}

\begin{abstract}
Illicit wildlife trafficking poses a threat to the conservation of species and ecosystems, and represents a fundamental source of biodiversity loss, alongside climate change and large-scale land degradation. Despite the seriousness of this issue, little is known about various socio-cultural demand sources underlying trafficking networks, for example the forthright consumption of endangered species on different cultural contexts. Our study illustrates how wildlife trafficking represents a wicked problem at the intersection of criminal enforcement, cultural heritage and environmental systems management. As with similar network-based crimes, institutions are frequently ineffective at curbing wildlife trafficking, partly due to the lack of information detailing activities within illicit trading networks. To address this shortcoming, we leverage official government records documenting the illegal trade of reptiles in Colombia. As such, our study contributes to the understanding of how and why wildlife trafficking persists across robust trafficking networks, which are conduits for a broader range of black-market goods. Leveraging geo-spatial data, we construct a multiplex representation of wildlife trafficking networks, which facilitates identifying network properties that are signatures of strategic trafficker behavior. In particular, our results indicate that traffickers' actions are constrained by spatial and market customs, a result which is apparent only within an integrated multiplex representation. Characteristic levels of sub-network coupling further indicate that traffickers strategically leverage knowledge of the entire system. We argue that this multiplex representation is essential for prioritizing crime enforcement strategies aimed at disrupting robust trade networks, thereby enhancing the effectiveness and resources allocation of institutions charged with curbing illicit trafficking. We develop a generalizable model of multiplex criminal trade networks suitable for communicating with policy makers and practitioners, thereby facilitating rapid translation into public policy and environmental conservation efforts.
\end{abstract}

Keywords: Wildlife trade, Reptile trade, Social network analysis, Green crime, Spatial network, Network disruption, Black market, Illicit economies

\section{Introduction}

\section{Concerning dimensions of wildlife trafficking}

Wildlife trafficking is a wicked problem affecting thousands of wild species (Robinson et al. 2015; Rosen and Smith 2010) and communities (Oldfield 2003; Wyatt 2013), and with the potential to expand toward new species and countries (Scheffers et al. 2019)

(c) The Author(s). 2020 Open Access This article is licensed under a Creative Commons Attribution 4.0 International License, which permits use, sharing, adaptation, distribution and reproduction in any medium or format, as long as you give appropriate credit to the original author(s) and the source, provide a link to the Creative Commons licence, and indicate if changes were made. The images or other third party material in this article are included in the article's Creative Commons licence, unless indicated otherwise in a credit line to the material. If material is not included in the article's Creative Commons licence and your intended use is not permitted by statutory regulation or exceeds the permitted use, you will need to obtain permission directly from the copyright holder. To view a copy of this licence, visit http://creativecommons.org/licenses/by/4.0/. 
as a multi-scalar phenomenon (see, Arroyave et al. 2014; Biggs et al. 2017; Broad et al. 2003; Patel et al. 2015). The convergence of ecological and socio-cultural dimensions of wildlife trafficking give rise to a management paradox at the intersection of wildlife conservation and cultural sustainability.

On the conservation dimension, trafficked species are commonly overharvested in response to strong demand, resulting in higher extinction risk (Auliya et al. 2016; Broad et al. 2003; Nijman et al. 2012; Scheffers et al. 2019). Indeed, species overexploitation is one of the most common causes for recent and future species extinction, alongside climate change and human-driven land degradation (Pimm et al. 2014; Pimm and Raven 2000). The spread of diseases (Karesh et al. 2007; Smith et al. 2012) and emergence of invasive species (Carrete and Tella 2008; García-Díaz et al. 2017) constitute additional threats for biodiversity, both related to wildlife trade. Negative effects of wildlife trafficking also pose concerns for other species, and ultimately entire ecosystems. ${ }^{1}$

On the sociocultural dimension, human communities rely on biodiversity products for their livelihood and development, ${ }^{2}$ especially in poor and malnourished countries ${ }^{3}$ (Mainka 2002). However, where wildlife trafficking takes place communities are frequently exposed to violence, corruption, cooptation of institutions, and additional forms of criminality (see Ayling 2013; Gaynor et al. 2016; Rosen and Smith 2010; Wyatt 2013). Institutions at national and global scales committed to combating wildlife trade ${ }^{4}$ are frequently weak and overflowed (Zimmerman 2003), and alternatives to tackle wildlife trafficking seem to be insufficient (Broad et al. 2003; Wyatt 2013). Alternative approaches include market manipulation (e.g. Drury 2009; Moorhouse et al. 2017), and community-base management of species (e.g. Biggs et al. 2017; Robinson et al. 2015), however the problem at large scales is unfrequently addressed.

Actors involved in wildlife trafficking and their roles (e.g. poachers-harvesters, middlemen, smugglers, retailers, buyers) are poorly defined and might vary in time, and in contextual and physical landscape (Duffy et al. 2016; Nekaris et al. 2010; Phelps et al. 2016). Moreover, actors are involved in social structures where wildlife trafficking and other crimes unfold (Gaynor et al. 2016). These considerations manifest in our study in two particular aspects. First, information regarding criminal networks, in particular

\footnotetext{
${ }^{1}$ Many diseases such as the Chytrid fungus are spread globally due to wildlife trade (Kolby et al. 2014). This disease have been reported as one of the major causes of decline in natural populations of amphibians globally (Lips 2016). Similarly, species such the lionfish have been introduced in ecosystems causing considerable reduction of native species (Morris and Whitfield 2009). Both examples illustrate derived effects of wildlife trafficking that affect other species beyond those actually traded. Due to the inter-dependency of ecosystems, it is expected that species and diseases introduced might cause impacts in the ecosystems as a whole.

${ }^{2}$ Species play a major role in local economies, rural gastronomy, and for cultural practices and beliefs (Rao et al. 2011). Although demand for species is usually associated to traditional medicines and bush meat, there are also large markets for trophies, pets, and other sumptuary uses (Arroyave et al. 2014; Patel et al. 2015). There is not a consensus regarding the value of these markets, estimations vary from some tens to hundreds of billions, annually (Chomel et al. 2007; Rosen and Smith 2010).

${ }^{3}$ Biodiversity is not homogeneously distributed around the globe. There is a strong correlation between biodiversity and poverty (Mainka 2002). Typically, diversity constitutes a temporary or permanent income for rural communities that commonly get trapped in the "tragedy of commons" (Copeland and Taylor 2009). In those cases, species tend be harvested up to exhaustion.

${ }^{4}$ International Agreements such the Convention on International Trade in Endangered Species of fauna and flora (CITES) were developed to control species trade and prevent overexploitation, however black markets and species laundering still threaten species (Patel et al. 2015; Rosen and Smith 2010). Similar initiatives can be found in a country-base, even though they have not succeeded in tackling wildlife trade. Two factor that could explain this are the ratio traffickers/institutions officers, and the fact that wildlife trade is wrongly considered as a minor issue in many countries (Wyatt 2013).
} 
individual behavior and collective social structures, are difficult to gather, if not inaccessible (Eman et al. 2009; Sageman 2014). Second, wildlife traffickers are not necessarily members of the underlying criminal organization, and so an additional challenge is the limited knowledge of traffickers' activities and strategies (Phelps et al. 2016; Scheffers et al. 2019), which are not necessarily coinciding with the activities and strategies of the overarching criminal organization. Together, a lack of information on the individual and social factors contributes to a resilient persistence of wildlife trafficking. Furthermore, despite best intentions, ineffective on-the-ground policing of wildlife trade may further impair both species recovery as well as the ability of communities to conduct traditional practices.

To address these multiple elements simultaneously, here we show how relatively simple techniques of multiplex networks analysis can be used to unveil patterns of trafficker action and to identify data-driven strategies for dismantling wildlife trafficking networks. Due to the difficulty that comes with tracking criminal structures such as wildlife traffickers' organizations, we thereby propose to evaluate trafficker behavior using spatial proxies. In particular, we leverage official government data recording the confiscation of wildlife products to evaluate illegal reptile trade in Colombia. We use a multiplex framework in order to evaluate how criminal activities, aggregated across multiple species, are projected across geographical space - understanding this not only as a representation of physical space, but also as the social, ecologic and economic landscapes that coincide. As such, our study contributes to the understanding of how criminal activity persists across illicit trade networks, its internal co-dependence, and its robustness.

\section{Multiplex features of wildlife trafficking}

Wildlife trafficking networks are fundamentally social structures. As such, they can be understood as ensembles of family ties, communication channels, money flux, formal and informal organizational agreements, and species flux (Bright et al. 2015; Nijman et al. 2012). In particular, ties in criminal structures, as well as in other social systems, involve material and symbolic contents (Borgatti et al. 2009; Lien and Law 2011). This multiplicity of content embedded in social ties has been called diffuseness (Granovetter 1977). Such intrinsically diffuse characteristics of criminal operations (e.g. secrecy, security handling, risk management, see Duijn et al. 2014; Niraj et al. 2012; Toth et al. 2013; Zimmerman 2003) impede an in-depth analysis of social tie multiplicity. Fuzzy roles, diffuseness and otherwise hidden characteristics of criminal networks render information pertaining to the structure of the social organization incomplete (Broad et al. 2003; Duijn et al. 2014; Oldfield 2003). However, alternative representations could inform how criminal structures operate and constitute criminal networks, and allow one to extract part of the content embedded in diffuse ties. For instance, spatial signatures of the operation (e.g. where crimes take place) may illuminate how criminal activities are developed, and across which physical and cultural structures they depend upon, among other characteristics (see, Campedelli et al. 2019; Graif et al. 2014).

Another defining feature of wildlife trafficking networks we analyze is the multi-type links connecting different regions (nodes). We argue that it is essential to model these networks using a multiplex network representation, whereby multiple networks coexist, 
being interdependent yet synergistic (Boccaletti et al. 2014). In the present case, multiple relations (e.g. communication, business ties) that differ in structure and dynamics converge in such a way that facilitates illicit trade across species, geographic landscapes. As such, different regions can play different roles in the trafficking network of different species, giving rise to a fully connected system when viewed all together.

Of particular relevance to our study, recent work shows that multiplex networks are more tolerant to random failures than their monoplex counterparts (De Domenico et al. 2014; Min et al. 2014). This insight highlights the importance of assessing the vulnerability (resistance to errors) and robustness (resistance to attacks) of networks in a multiplex perspective, especially in the context of multidimensional wicked problems that require broad approach across multiple facets. Recently, frameworks for evaluating multiplex and multilayered networks have been developed. For example, see Boccaletti et al. (2014) and related work for differences between multiplex, multilayered and interconnected networks, and conceptual foundations. Such frameworks have allowed for the description and improved understanding of processes embedded in layered systems. These approaches are quite relevant to multi-faceted problems deriving from criminal systems, such as wildlife trafficking.

Public and private interest in addressing wildlife trafficking has increased in recent years, as funder donors and researchers come together to develop strategies for policy enforcement and wildlife demand reduction (Ayling 2013; Biggs et al. 2017; Phelps et al. 2016; Wyatt 2013). Yet, there is an incomplete picture about the structure of the crime as well as in which ways wildlife trafficking can be effectively disrupted. Although political and technical resources have been deployed for tackling trafficking, asymmetries in terms of capabilities, resources and information between traffickers and institutions have led to the persistence of black markets of wildlife. Because increasing institutional capabilities is costly and politically demanding, henceforth often perceived to be infeasible in the short term, then novel strategies for enhancing the effectiveness of organized crime are both timely and relevant (Duijn et al. 2014).

The structure of our study is as follows. We first motivate the relevance of this case study, detail the data used, and define how we model this complex system using a multiplex representation based on spatial proxies. We then introduce the multiplex network framework and methods that are necessary for quantifying the structure and robustness of wildlife trafficking networks in Colombia. We then show empirical results compared with theoretical null models, which together facilitate identifying particular multiplex properties that give important insights into topological and structural properties related to the functioning of wildlife trafficking. Finally, we conclude with policy implications related to our findings. Overall, this work develops a technical strategy for improving the effectiveness of environmental institutions charged with controlling and disrupting wildlife trafficking, with the larger mission of social and environmental conservation.

\section{Methods}

The criminal nature of wildlife trafficking implies that social structures embedded in this kind of system can hardly ever be traced properly. Nevertheless, some operational traces of crime organizations can be identified, thereby facilitating the reconstruction of particular behavior and activity patterns. For example, how wildlife traffickers operate 
could be determined in part by characterizing those places where poaching and sales take place. In addition, relations between places emerge according to the routes that traffickers used when smuggling. Therefore, within our geographically embedded context, the trafficking network arises as a collection of spatial points (nodes) connected through movement of traffickers (links), as illustrated in Figs.1 and 2. Since traffickers navigate between these spatial nodes, there are physical, logistic, economic and social structures that support such activity. Thus, the connectivity of nodes configures a diffuse state in which several interactions are condensed (Fig. 1).

One can reasonably assume that nodes differ in their capabilities to support the supply and demand of a variety of species. Indeed, species are not homogenously distributed through space, and the same goes for factors that usually have been described as drivers of wildlife trafficking, such as cultural customs, economic disparities, and weak governance (Ayling 2013; Biggs et al. 2017; Brashares et al. 2011; Duffy et al. 2016). Accordingly, it could be expected that traffic routes differ between harvested species. Nevertheless, correlations in traffic routes across species can be expected due to variable specialization among traffickers, which could give rise to specific motifs of multispecies trafficking (see Fig. 1). Importantly, traffickers are frequently characterized as opportunistic actors (Brashares et al. 2011; Oldfield 2003; Sánchez et al. 2016). The trafficking of each species constitutes a network (plex), and several networks form a connected hyper-network (multiplex) due to the ability of traffickers to switch between species, and smuggle or sell multiple species simultaneously. Such simultaneous or exchange-based trade may arise from a lack of consumer preference reflecting a perceived substitutability between species (Oldfield 2003; Scheffers et al. 2019). Therefore, the multiplex behavior of wildlife trafficking comes from shared identical nodes across plexes, and connectivity and interdependence between plexes.

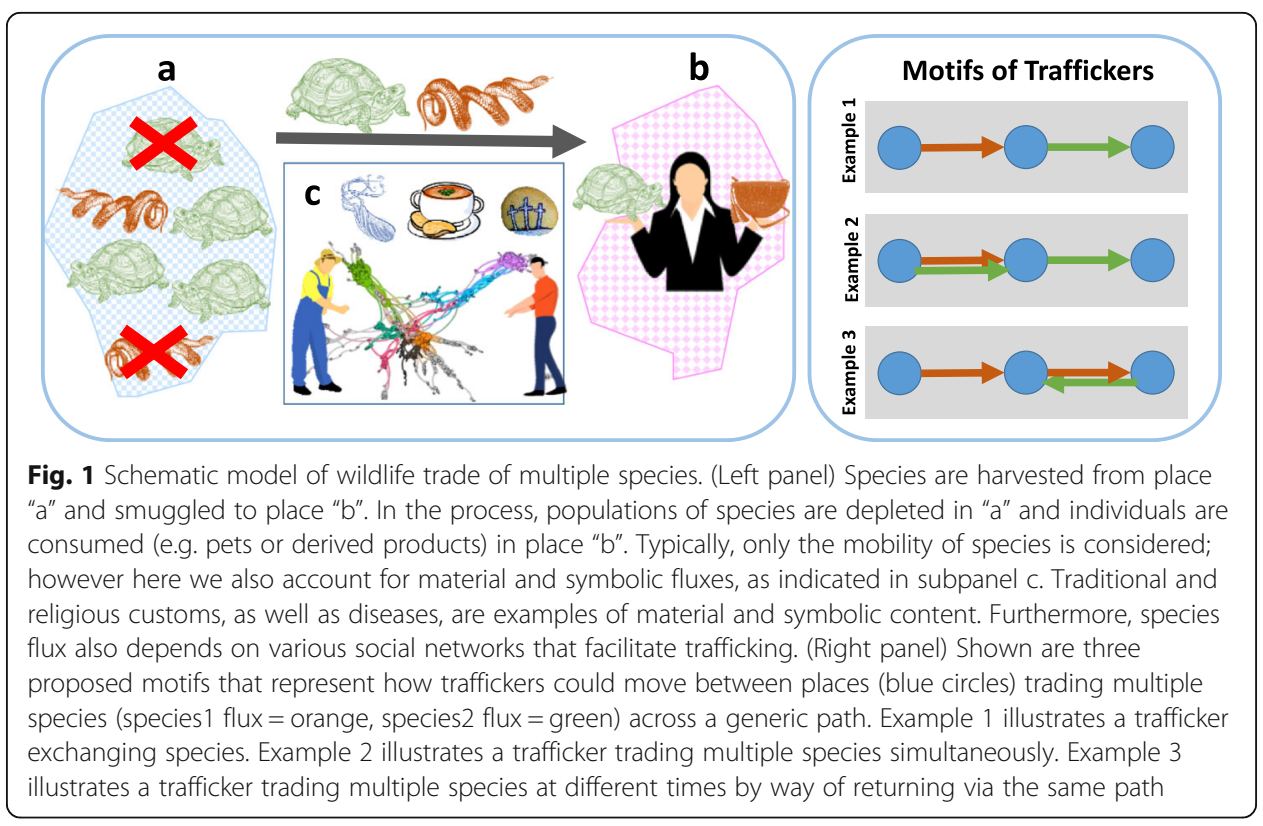



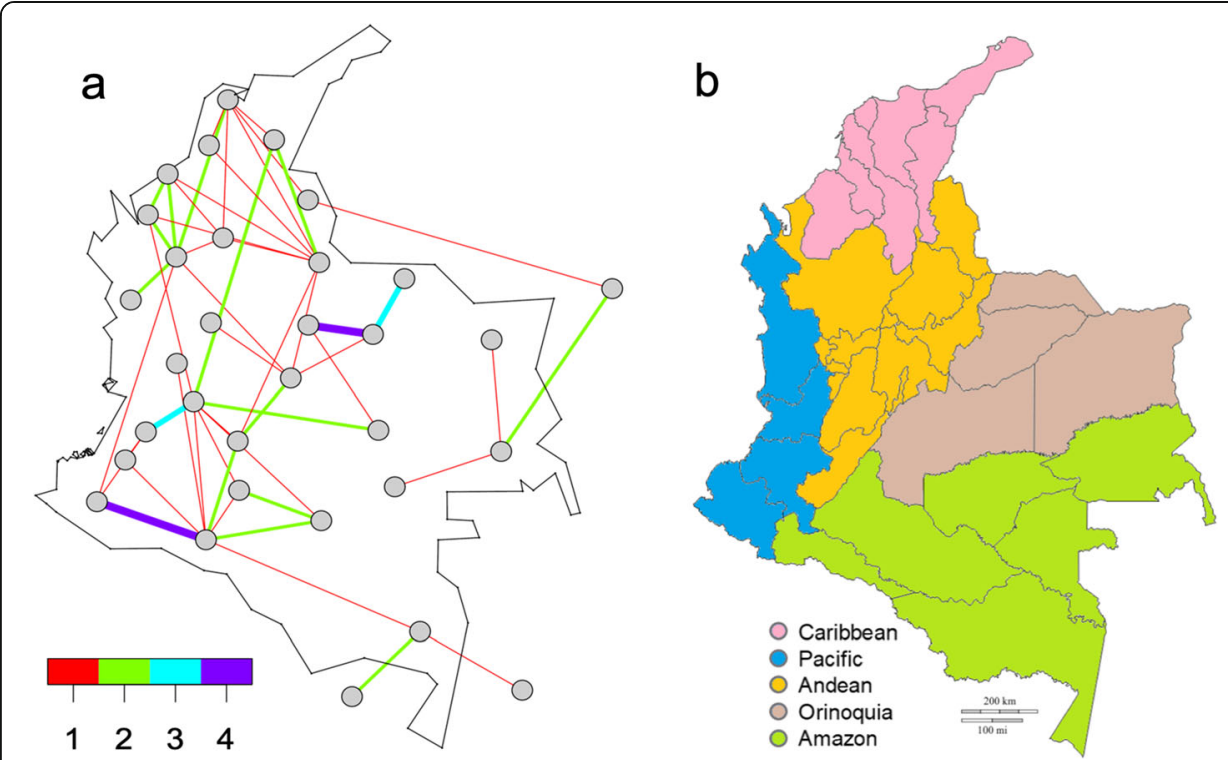

Fig. 2 Network representation of reptile trafficking in Colombia. a Nodes correspond to departments (national geopolitical subdivisions) and links indicate the number of reptilian families traded across each border, as indicated by the color scale. Nodes outside of the map border represent neighboring countries. b Administrative division of Colombia into departments. Colors indicate the dominant climate zone in each department. Social, economic and biotic similarities between departments is higher within than between regions

\section{Case study}

Colombia is one of the most biodiverse countries in the world. Climatic, topographic and historical factors explain such diversity, and at the same time contribute to the uneven and patchy distribution of species (Pimm et al. 2014). This biodiversity is also expressed in the cultural gradient that persists across the country (Aristizabal Giraldo 2000; Loh and Harmon 2005). Relatively high levels of wildlife diversity, spatial heterogeneity, human mobility, cultural diversity and economic disparity are factors contributing to the prevalence of wildlife trade (Brashares et al. 2011; Lindsey et al. 2013; Sánchez et al. 2016). Wildlife trafficking in Colombia is one of the most pressing conservation concerns for many groups of species, in particular for reptiles and birds (Rodriguez et al. 2008). In this study we focus our attention on reptiles, the most trafficked group and one of the most threatened ones in the country and worldwide (Robinson et al. 2015). Frequently, reptiles are traded in bulk quantities numbering in the thousands (Robinson et al. 2015; Rodriguez et al. 2008; Rosen and Smith 2010), as many reptiles play a central role in Colombian myths and beliefs, translating into gastronomic and economic demand (de la Ossa and de la Ossa-Lacayo 2011; Fals Borda 1979).

Regional environmental authorities and police corps, have been charged with developing control activities against wildlife trafficking throughout the country, resulting in confiscation of wildlife products, and administrative and punitive actions against traffickers. Yet information about environmental offenders is scattered and typically not accessible because of privacy and legal constraints within the punitive process. In contrast, records of confiscations are compiled by the Ministry of Environment and Development of Colombia (MEDC). These records include information about the source 
and destination of shipment seized, as well as the taxonomic identity of the species confiscated. Here we analyze available records spanning the 5-year period 2005-2009. While the MEDC is currently developing an information system for improved mapping and monitoring wildlife trafficking, such developments are resource intensive; as such, the data used here is the latest data released.

Based upon these confiscation records, we are able to construct a multiplex network of reptiles trafficking in Colombia. To be specific, nodes correspond to departments (equivalent to states or provinces), links correspond to source-destiny record of shipments, and each plex corresponds to the traffic of a taxonomic family of reptiles. We use taxonomic families (hereafter referred to as families) to reduce uncertainties associated with misidentification of specimens, while also considering that members of the same family typically share uses and cultural meaning. Families of reptiles analyzed here accounts for more than an $80 \%$ of all reptile trafficking in Colombia and include tortoises (5 families), iguanas ( 1 family), snakes and vipers ( 3 families), and Caymans (1 family). More information about the families is provided in Supplementary Note 1 (SN 1).

All together, this multiplex network is composed by 34 nodes and 10 plexes. Figure 2 illustrates an aggregated representation of this multiplex. Trafficking statistics and network measures by department of the aggregated representation can be found in Supplementary Table 1 . The climate zones shown in Fig. 2b represent 5 larger biogeographical regions, each with characteristic cultural, ethnic, social, economic and climatic similarities within. Overall, species are mostly trafficked from lowlands (e.g. Caribbean and Amazon regions) to the Andean region, where population, wealth and infrastructure are more concentrated, and where abundance of reptiles is low. The number of families trafficked by department is weakly correlated with the network's properties $\left(R^{2}<0.32\right)$ or the number of confiscations $\left(R^{2}<0.13\right)$ (see SN 2), which indicates that the data is appropriately capturing trafficking dynamics, and at most only weakly biased by department-specific policing and reporting factors.

\section{Network framework and metrics}

Different multiplex frameworks have been developed to address different assumptions and contexts. The relevant framework implemented here is based upon the adiabatic projection, introduced by Cardillo et al. (2013). This framework consists of evaluating changes within the structure of aggregated (projected) networks constructed from different permutations of plexes. In our case, reptile trafficking is composed by $N=34$ nodes and $M=10$ plexes, where $m_{i}$ is a projected network defined as $g^{m_{i}}\left(N, \mathcal{L}^{m_{i}}\right)$, being $\mathscr{g}^{m_{i}}$ a graph with $N$ nodes and $\mathcal{L}^{m_{i}}$ directed links between nodes. Plexes are aggregated across $m$ levels, each one containing $\left(\begin{array}{c}m \\ M\end{array}\right)$ possible $m_{i}$ projections obtained by merging $m$ plexes. In each level of combination, several network metrics are calculated over all possible combinations. Further details on adiabatic projection of multiplex networks can be found in Cardillo et al. (2013) and Lotero et al. (2016).

Recent advances in the analysis of multiplex networks have incorporated tensorial representations of the multiplex (e.g. Boccaletti et al. 2014; De Domenico et al. 2014, 2015b). This improvement facilitates considering the role of inter-plex connectivity, thereby preserving the relative independence and identity of each plex. These advances 
have promoted new ways of undertaking the centrality of nodes (see nodes versatility in De Domenico et al. 2015b) and emerging dynamics such as synchronization or multiplex diffusion (Boccaletti et al. 2014; Gómez et al. 2013). Despite the valuable contribution of this novel tensorial representation, we followed Cardillo et al. (2013) approach for two main reasons. First, the adiabatic projection framework allows us to easily characterize the effect of increasing the set of species analyzed. Typically, antitrafficking policies are based upon single or aggregates of small groups of charismatic species (see Patel et al. 2015). We argue that such species do not necessarily have an umbrella effect over other relevant and largely traded species, and so it is crucial to consider all species simultaneously. Second, technical and conceptual simplicity of adiabatic projections is more accessible for a broader set of stakeholders, such as environmental policy makers, wildlife trafficking police, and other potential audiences. Nevertheless, we include some tensorial metrics into our analysis in order to compare the effect of incorporating more complex measures as strategies for attacking networks, as we describe below.

For all $m_{i}$ projected network we calculate a set of metrics that account for structural and topological properties of the graph. Although significant advances in defining measures of weighted networks have been made, we consider the projected networks as unweighted graphs so as to simplify the interpretation of the analysis. Metrics included in the analysis are: Density $(D)$, Clustering coefficient $(C)$, Average path length $(l)$, Diameter $(d)$, Size of giant component $(S)$, maximum Degree centrality $\left(k_{\text {Max }}\right)$ (differentiating between in-degree and out-degree), Degree centralization $\left(C_{k}\right)$, Betweenness centralization $\left(C_{b}\right)$, Link overlapping $(O)$ and reciprocity $(R)$. Descriptions and mathematical formulations of network metrics used are provided in SN 3.

In addition, we compare the result of empirical projections with three null models. These null models consist of random networks that conserve some properties of the empirical ones. Model 1: is constituted by simulations of $M$ Erdos-Renyi random networks (Erdös and Rényi 1960) of size $N$, each one preserving the same amount of edges than the empirical networks. The $M$ random networks were projected without additional randomization. This model evaluates whether our empirical networks and the projections lack topological structure, and whether our results are spurious manifestations related to graph density. Model 2: projects random networks equivalent to the empirical one in terms of their degree sequence (in/out). This second model assesses the effect of degree distribution on the overall structure across all projections. Model 3: is produced by random networks in which the origin of trade flux is conserved, and the links are traced to a neighboring department according to the physical adjacency of departments. This model represents a limited ability of traffickers to reach long distances and a prevalence of trading in the vicinity. We produce 2500 simulations for each model and report every realization across all synthetic configurations.

In addition to the null models we compare the inter-annual aggregated behavior of the multiplex with the multi-annual aggregates so as to identify temporal consistency of our results. As such, we project the networks using the cumulative sequence of years in which we aim to detect how the trafficker's behavior is related to pre-existing routes and structures.

We further evaluate the robustness of the multiplex network by producing sequential attacks or node removals on the projected networks. We use different strategies of 
disruption based on nodal centrality, including degree, betweenness, closeness, eigenvector and Pagerank centralities. In spite of many strategies having been proposed for dismantling networks (Ren et al. 2019; Wandelt et al. 2018) we limit our exploration to the most common strategies. Furthermore, these strategies constitute feasible cases for implementing real-world scenarios, which are thus largely valuable to public policy. In addition, a random removal strategy was implemented.

Sequential attacks consist of removing the node with the largest centrality in the projected network and after each attack the centrality is recalculated, then the process is repeated until all nodes become disconnected. In each step we calculated the fraction of nodes intentionally removed and the fraction of nodes disconnected. Previous works that have assessed the robustness of networks only consider the fraction of nodes connected to the largest component instead to any connected component (Wandelt et al. 2018). We consider that small connected components representing local or regional markets still might foster overharvesting of reptiles and promote diffusion of information and goods (Duijn et al. 2014). In our case we define robustness as the area under the curve produced by the fraction of nodes removed and the fraction of disconnected nodes. This approach enables us to reduce the effect of attacking diads and triads.

Finally, in order to compare the effectiveness of strategies commonly used in monoplex networks (centrality metrics) and strategies based on the multiplex connectivity of nodes (versatility), we combine adiabatic projections and tensorial representation of multiplex networks. In this regard, at each level of combination $m \geq 2$, the networks were not aggregated but represented as a tensor instead. Following the previous rationale, node versatility (using Eigen Tensor and Multiplex PageRank forms, see De Domenico et al. 2015b) is calculated, and the most versatile node is removed across all the plexes. This is repeated up to the point that all nodes become disconnected within all plexes. For each metric we run 2500 simulations. All the methods described were conducted in R (R Core Team 2017) using the packages "igraph" (Csardi and Nepusz 2006) and "muxVizR"(De Domenico et al. 2015a).

\section{Results and discussion}

\section{Underlying wildlife trafficking mechanisms - multiplex insights}

In what follows, we identify and discuss relevant characteristics of the empirical multiplex wildlife trafficking network that are not reproduced by the null models considered here. While some metrics are largely explained by our null models, such as density (Fig. 3a) and the size of the largest component (Fig. 3b), which increase systematically, ${ }^{5}$ we do identify informative properties belonging principally to the empirical multiplex. Such distinguishing characteristics offer valuable insights into the role of geographic constraints and the strategic behavior of traffickers, together pointing to feasible mitigation strategies.

We start with network metrics such as average path length (Fig. 3d), degree centralization (Fig. 3e) and maximum degree (Fig. 3g-i), which are well explained only

\footnotetext{
${ }^{5}$ Aggregation enlarges network metrics such as density (Fig. 3a), the size of the largest component (Fig. 3b), clustering coefficients (Fig. 3c), and maximum degrees (Fig. 3g-i) due to inherent increases in the number of edges in projected networks, indicating differences between the trafficking of each family (i.e., individual plexes). This systematic result of aggregation has been previously reported in analyses on other systems (Cardillo et al. 2013; Lotero et al. 2016).
} 


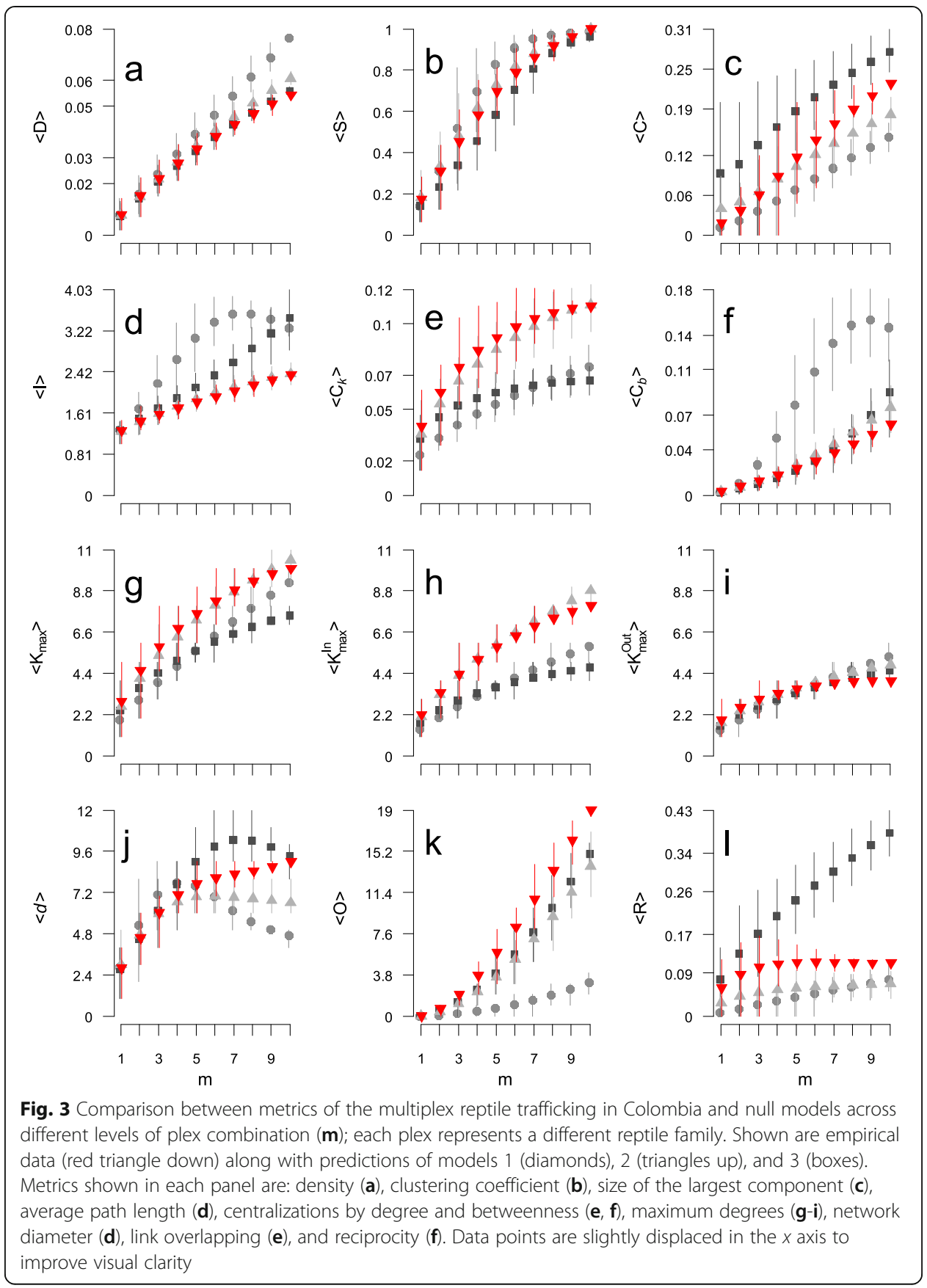

by null Model 2, indicating that part of the behavior of the system is the result of idiosyncratic features of departments (i.e. nodal connectivity). In contrast, clustering coefficient (Fig. 3c), diameter (Fig. 3j) and betweenness centralization (Fig. 3f) metrics show that at a low levels of plex combination $(m)$ the empirical multiplex structure can be fully explained by the null models; nonetheless, for large $m$ there are notable differences. In particular, the empirical multiplex exhibits more triangles (except for comparisons with model 3), larger paths between the most distant nodes in the multiplex structure, and the importance of high throughput nodes (or "bridges") are more evenly distributed. Since such characteristics become evident only when multiple families are 
considered into the analysis, our results highlight the importance of integrating all available trafficking data for all species in the analysis of wildlife trafficking.

Interestingly, metrics such as link overlapping (Fig. 3k) and reciprocity (Fig. 3l) exhibit large deviations from most null model predictions, even for small $m$. This result suggests that traffickers use common routes for smuggling reptiles as well as back and forth trading.

We find that null models 2 and 3 are able to reproduce great part of overlapping links but not all of them, suggesting that the use of common routes for trafficking species may largely be captured by the empirical vicinity structure of departments and the amount of connections that they have. Although model 3 is able to explain part of the link overlapping, it largely fails to reproduce link reciprocity, instead overestimating this metric. Similar patterns are observed for other metrics. Model 3 suggests that the spatial organization of departments is relevant for the navigability of traffickers; yet, we observe strong directionality toward high demand departments, mostly located in the Andean region. Consequently, we argue that back-and-forth trading and alternative routes are less prevalent than what is expected in a predominantly regional market.

Despite a relatively high clustering of reptile trade (with respect to models 1 and 2), which suggests the use of alternative routes for trafficking reptiles, comparisons based on link overlapping and reciprocity metrics indicate that there are some routes extensively used in this regard. Similarly, the difference in clustering between the empirical data and model 3 suggest that some routes are avoided by traffickers. The clustering could be also explained by commercial circuits formed by the trade of multiple species, in particular in the northern region (Fig. 2).

In general, we show that the three archetypical motifs of multi-species trafficking introduced in Fig. 1 can be identified in our case study and play an important role in defining the multiplex structure. Indeed, these three motifs are supported by the most meaningful metrics assessed. To be specific, the enlargement of network diameter supports the idea of sequential trading (Example 1), while the trafficking of multiple species simultaneously (Example 2), and the back and forth trading (Example 3) are well supported by link overlapping and reciprocity, respectively.

Considering that wildlife trafficking networks could be dynamic and adaptive, as other criminal organization, we performed a temporal analysis of the empirical multiplex (Fig. 4). For most of the cases, all the cumulative time windows follow a similar growing behavior and the differences between windows correspond to discrepancies in magnitude, indicating that there are not dramatic changes in the system over time that deform the aggregate behavior. However, noticeable discrepancies between windows are shown in the lasts ones, as such the system become more connected and clustered. Such difference can be attributed to imbalances in the amount of records and families traded in each year (see ST 2). The temporal structure of density (Fig. 4a), betweenness centralization (Fig. 4f), link overlapping (Fig. 4k) and reciprocity (Fig. 4l) are particularly interesting, while other metrics do not show large differences between the windows 2005-2008 and 2005-2009, these metrics indicate noticeable changes in the traffickers behavior in 2009 that consist on the more extensive use of pre-existing routes and an increase in the back-and-forth trading. As such, bridges, common paths and reciprocal links emerge through the inter-annual relation of the multiplex. This 


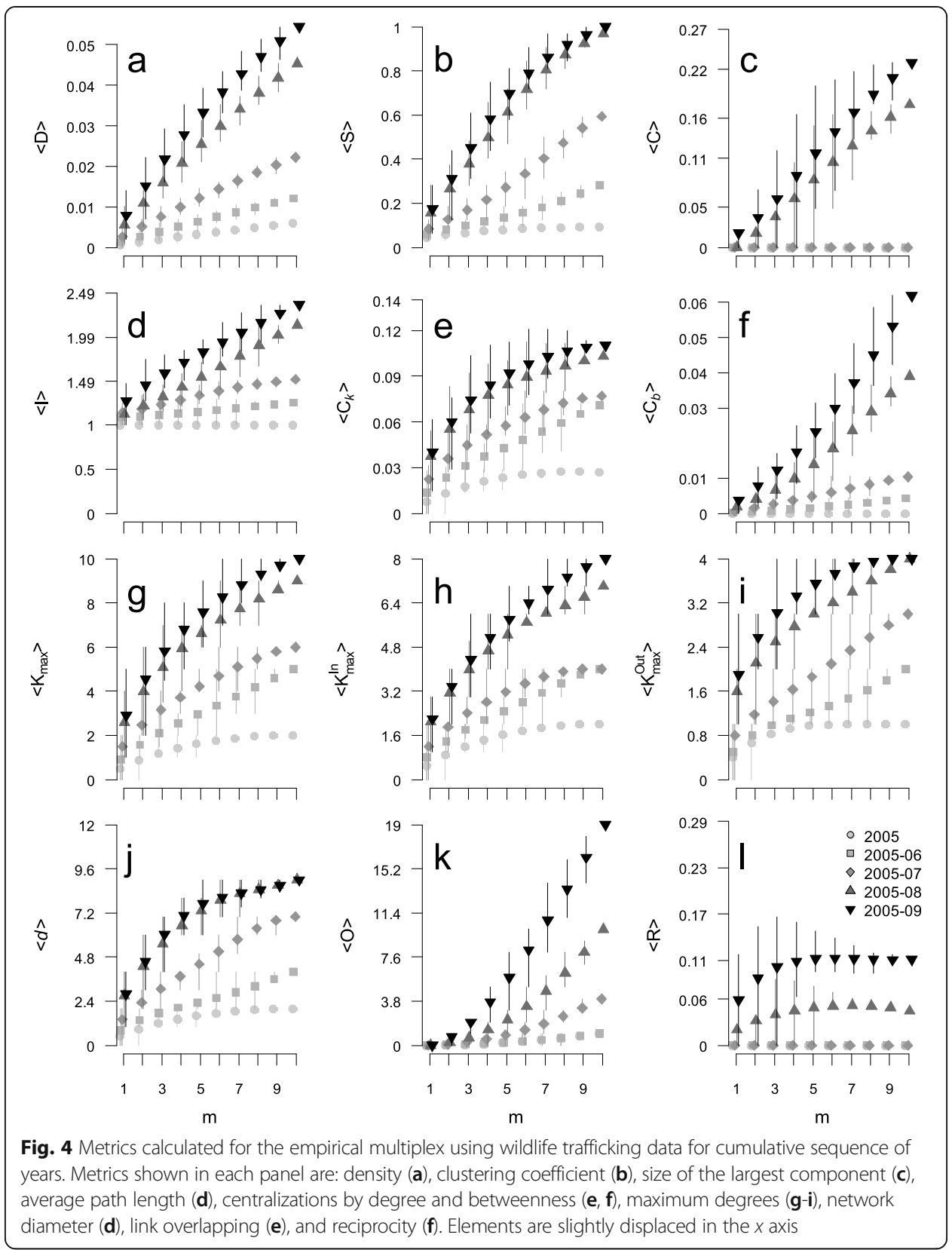

result suggests some ability of traffickers to identify accessible routes and make decisions accordingly.

We argue that the quantity of information when disaggregated by years may influence some of the results, especially in the period 2005-2006 when the information is less abundant. As such, temporal dynamics of trafficking require further investigation, in particular with regard to the reinforcement and generation of routes. In addition, we run the null models for the time window 2005-2008 (SF. 1) and our result are consistent with the 2005-2009 aggregate, tough differences between the empirical multiplex and the predictions of the null models are smaller than the observed in the 2005-2009 window. This suggests that patterns shown are descriptive of the system, and significant part of the system's structure is observed in the largest part of the dataset. 
In summary, differences between empirical data and null models, along with the temporal variation in multiplex characteristics indicate: (1) traffickers may know and prefer some routes, upon which smuggling species could be expedited, and there is some collective memory that enables participants to traffic more species along such routes. This idea is supported by the large link overlapping and the inter-annual composition. (2) Reciprocal trading involving multiple species indicates some degree of substitutabilitycomplementarity ${ }^{6}$ between species, especially in sub-regional markets. However, small marginal differences in reciprocity when more and more species are considered suggests an incomplete substitutability between species; this may be related with either the differences in their uses or their disjoint distribution. (3) Idiosyncratic connectivity might be caused by geographical features (e.g. neighborhood structure, infrastructure available, species distribution, "barriers" imposed by strong institutions, social landscape) that restrict traffickers' operation. Indeed, vicinity structure notably influences some dynamics of trafficking between neighboring departments, probably conducted by terrestrial and fluvial means, reinforcing regional markets that ultimately expand to adjacent regions. (5) Considering the trafficking of each reptile family in isolation can yield misleading results, since for many metrics null models are able to explain quite well the empirical data for small $\mathrm{m}$; thus, a multiplex approach is required for revealing meaningful patterns. In addition, adequate temporal frames and longitudinal analysis are needed to capture relevant dynamics as repeated (overlapping) and back-and-forth (reciprocity) trading, that otherwise could be highly underestimated.

Additional characteristics of the system could serve as explanatory factors of the dynamics of trafficking. For instance, it has been reported in analysis based on singlespecies trafficking that market structure is associated with geographic distribution of species, regional cultural heritage, and economic disparities between supply and demand places (Arroyave et al. 2014; Bonilla et al. 2012; Brashares et al. 2011; Sánchez et al. 2016). Increasing the number of families (plexes) considered within our analysis contributes to the understanding of a larger picture of wildlife trafficking in the country. Although analysis developed independently for each family could reveal some nuances of species uses and trafficking dynamics, such approaches do not capture the breadth of variation, which may result in an incomplete representation.

\section{Multiplex robustness and strategic policing for optimal trade disruption}

We implemented various network attack strategies motivated by different rationalities for disrupting criminal structures. Strategies based upon prominence of nodes (Eigenvector centrality, EigenTensor versatility) address places closely connected to strategically connected markets. Attacks based on the nodal prominence and the directionality of fluxes (PageRank centrality and Multi-PageRank versatility) focus on those places that receive illegal trade from strategic markets. Other strategies rely on attacking places with high ability to connect distant places (betweenness and closeness centralities) or that act as bridges or gateways. Finally, one strategy focuses on highly connected nodes (degree centrality) independent of the network's neighborhood structure.

\footnotetext{
${ }^{6}$ For instance, species as "hicotea" or "Colombian-slider" tortoise and iguana are used as dishes during the Easter celebration in northern regions of Colombia. Despite that they share geographical distribution and given meanings, trafficking networks at the regional scale are developed to supply the demand of urban areas from neighboring places. In this case, species show complementary uses.
} 
Consistent with expectations, we find that plex aggregation (corresponding to increasing $\mathrm{m}$ ) increases the multiplex robustness (Fig. 5), mainly due to increasing link density (Callaway et al. 2000; da Cunha and Gonçalves 2018; Duijn et al. 2014; Min et al. 2014). In all cases, strategies performed better than random strategies and the surplus gained by strategies increases with $\mathrm{m}$ (subpanel in Fig. 5). For most of the cases, centrality measures such as Degree or PageRank have the best performance, even though there are not noticeable differences between strategies. In general, strategies based on node versatilities did not outperform strategies based on centralities, as expected. Closed walks or trapping nodes could contribute in explaining this behavior. We notice also that there is not a strong correlation between Multi-PageRank versatility and degree centrality in projected networks (see SF. 2) which implies that removing largely versatile nodes is not necessarily conducive to disconnecting a great fraction of nodes, but it might contribute to fragmenting the network (i.e. produce a larger number of small connected components frequently under-considered in analysis of robustness).

Our findings suggest that all strategies evaluated for disrupting illegal trade of reptiles in Colombia are almost equally useful in that regard. Despite that the simplest strategy based on the total degree of nodes do not show the largest performance, it produces similar outcomes when compared with more sophisticated strategies, specifically Pagerank centrality. Similar to (Wandelt et al. 2018), strategies based on degree sequences are not necessary optimal solutions, but they are quite efficient. Highly connected nodes correspond to places with both incoming and outgoing trade flux, but with predominance of large in-degree; thus, these nodes correspond to departments where species are consumed. Most of these departments are located in the Andean region or its interface with other regions. Although those regions may function as both suppliers and consumers of reptiles, it is more likely that they correspond to places devoted to consumption of species due to the fact that incoming links tend to contribute the most in the total degree (see Fig. 3g-i). As such, departments in the border of the Andean

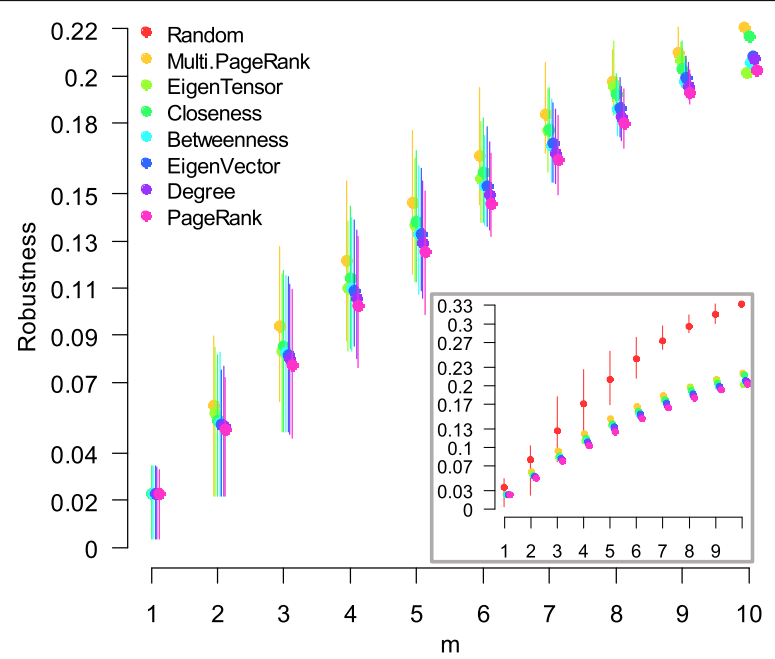

Fig. 5 Robustness of multiplex networks of reptile trafficking in Colombia. The resistance to targeted network attack is shown across all levels of plex combination (m) for different disruption strategies based on node centralities and versatilities. Elements are slightly displaced in the $x$ axis. Subpanel shows the average result of the strategies in comparison to random node-deletion interventions (i.e. attacks) 
region result in good candidates for intervention due to the fact that they contribute largely to the vulnerability of the multiplex.

Our analysis also points to the value of strategies based on simple metrics, such as degree centrality, as the information required to identify highly connected nodes is easily accessible by either using data derived from policing activities and reports, as implemented here, or by gathering experiences and knowledge from institutions and their staff, who are involved daily in monitoring and controlling wildlife trafficking. As such, regional policing activity aimed at disrupting traffickers by way of simple metrics should be prioritized, as it does not require large investments in training skilled staff, and could produce similar outcomes to more demanding strategies. In contrast, lack of knowledge related to the structure of the network could lead to ineffective interventions (closely aligned to random interventions). However, we recognize that the cost of intervention in nodes is not homogeneous and that could affect the implementation of dismantling strategies. Solutions such as those proposed by (Ren et al. 2019) need to be assessed in the future.

Targeted intervention (policing) of nodes where demand for reptiles is concentrated, in particular those in the border of the Andean region, seems to be effective for disrupting trafficking networks at the departmental scale in Colombia, though concrete actions are necessary to achieve such a goal. Literature in criminology and networks disruption has conceptualized elements for dismantling illegal structures (da Cunha and Gonçalves 2018; Duijn et al. 2014; Eman et al. 2009; Roberts and Everton 2011; Sageman 2014; Wyatt 2013; Zimmerman 2003). In particular, Roberts and Everton (2011) show that multiple actions are needed for imposing long-lasting effects on criminal networks, including kinetic (e.g. identifying and processing heads of organizations, disrupting channels of communication by capturing supporters) and non-kinetic approaches (e.g. rehabilitation of members like providing economic alternatives can disengage participation; discouraging the consumption of wildlife). In the present case, this represents prosecution of traffickers and vendors, identify stocking places and discouraging species consumption and even harboring. In other words, policies and interventions that leverage the diffuseness of trafficking networks to significantly perturb the embedded social and human capital are needed (Duijn et al. 2014). To this end, identifying valuable targets and their supporting structures (e.g. infrastructure, communication, social ties) can be developed if concerted efforts are prioritized toward those places where the system is most susceptible.

In order to curb wildlife trafficking, there is increasing need for improved cooperation between environmental authorities, criminal investigators and law enforcement, combined with extensive consumer-side education, which has been implemented with demonstrated success (Drury 2009; Moorhouse et al. 2017). Although these actions are demanding and hard to address at large scales, our findings provide a framework for defining priority sites for initial actions. In addition, we recommend that local supplyside interventions should be implemented in sync with demand-side education programs in order to disrupt the entire supply chain. Some of these initiatives (e.g. Biggs et al. 2017; Cooney et al. 2018) could contribute to reducing the market for wildlife products and at the same time reinforce and recognize cultural values, promote sustainable uses of wild species and strengthen different forms of governance, in particular those community oriented (Brondizio et al. 2009). 
In summary, we identify several relevant elements of wildlife trafficking that may contribute to the understanding of network-based green crimes, and criminal activity in general. First, reptile trafficking in Colombia is constrained by physical, social and market elements that provide structure. These geographic constrains are similar to what has been reported for cocaine smuggling in Central America (Magliocca et al. 2019), showing some similarities across crimes. As such, demand-supply interactions draw the routes that traffickers use and enable an up-scaling of their activities from regional to national levels. This is supported to a great extent by considering the simultaneous trade of multiple species, which is driven in part by the vicinity structure of departments and their idiosyncratic connectivity, and the knowledge that traffickers apparently have about market structure and routes for smuggling, that are used across species and time. The superposition of routes not only indicates an associated knowledge or preference, but also geographical elements (e.g. weak institutions, infrastructure that lacks official control labor, particular ecosystems with abundant species) that could enable/constrain the action of traffickers. The market's demand side contributes to this superposition mainly because trafficking routes converge where consumption of wildlife products is focused. This indicates the presence of an oligopolistic organization, as Harvey et al. (2017) previously suggested for the case of ivory trade in China. Market constraints can be attributed to the uneven distribution of species at the country scale, which causes the system to be poorly connected, giving rise to long path lengths. Regional affinities in biotic and cultural heritage terms, as well as the physical connectivity, support small scale clusters of trafficking for many species showing that drivers of wildlife use and trade are relevant elements for traffickers' operations. Indeed, economic asymmetries between source/destination places leverage the trafficking at national scale.

Second, similar conditions contribute to the robustness of the system, which increases when more species are considered (i.e. increasing $\mathrm{m}$ ). Multiple strategies are useful for attacking the underlying social structure of traffickers, even though simple strategies based on the number of market partners are as effective as more sophisticated ones. This is important because these findings could be easily translated into public policy. However, the inter-annual variation on reptile trafficking indicates that strategies should be permanent and target many species.

By way of example, simple information about trafficking dynamics gathered through official records or to some extent by compiling experiences of practitioner could have a significant impact on the ability of institutions to define places of interest and to henceforth disrupt illicit trafficking. Our analysis allows institutions to focus efforts like law enforcement and education on the demand side where the system as a whole is most susceptible, whereas community-based strategies could be implemented as alternatives for local development, engagement and cultural heritage conservation. As Duijn et al. (2014) and Roberts and Everton (2011) suggest, multiple actions of diverse nature must be taken repeatedly in order to achieve long-lasting disruptions. Reducing wildlife trafficking represents a significant advance in human and animal well-being, nonetheless it requires planned actions.

Here we show why it is necessary to include many species into the analysis and abandon the idea of umbrella species as a key element for understanding inner structures of wildlife trafficking networks. Similarly to Scheffers et al. (2019), we show that species- 
based policies could result in a large set of unattended issues due to oversimplification and unconsidered interactions between trafficking groups and species substitutability. As a result, we highlight the importance of systematically analyzing multiple species simultaneously - including non-charismatic - in order to fully appreciate the multiplex structure of the entire system.

\section{Conclusions}

One of the major hindrances to analyzing and curbing criminal activity is limited access to information concerning the crime itself. Here we show that spatial proxies are relevant for undertaking structural elements of crimes that account for general patterns of action of criminals as well as physical, biological, social, cultural and economic constraints. The multiplex methods utilized in this work facilitate identifying characteristics of the criminal operation that could be either inaccessible due to limited data availability or otherwise indistinguishable from randomly generated information.

Moreover, this work highlights the importance of including multiple facets of the criminal practice and its real-world implications - in both society and nature. Even the use of simple techniques for the analysis of multiplex networks such as adiabatic projections in addition to null models prove relevant for understanding the emergence of structural and dynamic characteristics of illegal systems such as wildlife trafficking. Actually, the simplicity of the method applied here may contribute to assessing the weaknesses of the criminal structure and therefore provides a useful and straightforward framework for designing interventions to disrupt organized crime networks. This is not only advantageous for translating science into societal outcomes, but also for improving our capabilities to understand other crimes, including green crimes like illicit logging or dumping, among others.

Increased efforts and methods to curb wildlife trafficking are needed, in particular to address idiosyncratic country- and species-specific factors that may limit the generalizability of certain approaches. Here we contribute to these efforts by applying methods of network science to a large temporal dataset capturing a real-world 'wicked' problem existing at the nexus of organized crime, cultural preservation and wildlife/environmental conservation. The results of our analysis provide support for basic network-based strategic interventions that prioritize the finite resources present in many regions of the world facing illicit black-market trafficking.

\section{Supplementary information}

Supplementary information accompanies this paper at https://doi.org/10.1007/s41109-020-00262-6.

Additional file 1.

We thank University of California and Universidad Nacional de Colombia for they support. In particular, FA thanks Universidad Nacional de Colombia, project [HERMES 19010] (2015) that partially funded his master studies. We also show gratitude to lab-members in both universities, who enriched the manuscript, especially to Oscar Romero by his carefully reading and insightful comments. We thank two anonymous reviewers for their comments that greatly improved the manuscript. 


\section{Funding}

Not Applicable.

\section{Availability of data and materials}

Data and code is available at https://doi.org/10.6071/M3RQ38. Data and code will be also available from the corresponding author. Reasonable questions about code can be directed to F.A.

\section{Competing interests}

The authors declare that they have no competing interests.

\section{Author details}

${ }^{1}$ Environmental Systems, School of Engineering, University of California, Merced, CA 95343, USA. ${ }^{2}$ Department of Physics, Faculty of Sciences, Universidad Nacional de Colombia, Bogotá, Colombia. ${ }^{3}$ Management of Complex Systems Department, Ernest and Julio Gallo Management Program, School of Engineering, University of California, Merced, CA 95343, USA.

Received: 23 October 2019 Accepted: 11 March 2020

\section{Published online: 31 March 2020}

\section{References}

Aristizabal Giraldo S (2000) La diversidad étnica y cultural de. Un desafío para la educación. Pedagogía y Saberes, Colombia https://doi.org/10.17227/01212494.15pys61.68

Arroyave F, Romero Goyeneche OY, Bonilla Gomez MA, Hurtado Heredia RG (2014) Illegal trade of tortoises (Testudinata) in Colombia: a network analysis approach. Acta Biológica Colombiana 19:381-391

Auliya M, Altherr S, Ariano-Sanchez D, Baard EH, Brown C, Brown RM, Cantu J-C, Gentile G, Gildenhuys P, Henningheim E (2016) Trade in live reptiles, its impact on wild populations, and the role of the European market. Biol Conserv 204:103-119

Ayling J (2013) What sustains wildlife crime? Rhino horn trading and the resilience of criminal networks. J Int Wildlife Law Policy 16:57-80

Biggs D, Cooney R, Roe D, Dublin HT, Allan JR, Challender DW, Skinner D (2017) Developing a theory of change for a community-based response to illegal wildlife trade. Conserv Biol 31:5-12

Boccaletti S, Bianconi G, Criado R, Del Genio Cl, Gómez-Gardenes J, Romance M, Sendina-Nadal I, Wang Z, Zanin M (2014) The structure and dynamics of multilayer networks. Phys Rep 544:1-122

Bonilla MA, Luque N, Cuervo MA, Barreto LC, Zuluaga C, Vásquez EA (2012) Tortugas terrestres y de agua dulce de Colombia y manejo de los decomisos. Ministerio de Ambiente y Desarrollo Sostenible. Universidad Nacional de Colombia, Bogota, Colombia

Borgatti SP, Mehra A, Brass DJ, Labianca G (2009) Network analysis in the social sciences. Science 323:892-895 https://doi.org/ 10.1126/science.1165821

Brashares JS, Golden CD, Weinbaum KZ, Barrett CB, Okello GV (2011) Economic and geographic drivers of wildlife consumption in rural Africa. Proc Natl Acad Sci 108:13931-13936 https://doi.org/10.1073/pnas.1011526108

Bright DA, Greenhill C, Ritter A, Morselli C (2015) Networks within networks: using multiple link types to examine network structure and identify key actors in a drug trafficking operation. Global Crime 16:219-237

Broad S, Mulliken T, Roe D (2003) The nature and extent of legal and illegal trade in wildlife. In The trade in wildlife. In Oldfield, S. (2003). The trade in wildlife: regulation for conservation. London: Earthscan Publications 3-22 ISBN 1-85383-959-0

Brondizio ES, Ostrom E, Young OR (2009) Connectivity and the governance of multilevel social-ecological systems: the role of social capital. Annu Rev Environ Resour 34:253-278

Callaway DS, Newman MEJ, Strogatz SH, Watts DJ (2000) Network robustness and fragility: percolation on random graphs. Phys Rev Lett 85:5468-5471 https://doi.org/10.1103/PhysRevLett.85.5468

Campedelli GM, Cruickshank I, Carley KM (2019) A complex networks approach to find latent clusters of terrorist groups. Appl Network Sci 4:59

Cardillo A, Gómez-Gardenes J, Zanin M, Romance M, Papo D, Del Pozo F, Boccaletti S (2013) Emergence of network features from multiplexity. Sci Rep 3:1344

Carrete M, Tella J (2008) Wild-bird trade and exotic invasions: a new link of conservation concern? Front Ecol Environ 6:207-211

Chomel BB, Belotto A, Meslin F-X (2007) Wildlife, exotic pets, and emerging zoonoses. Emerg Infect Dis 13:6

Cooney R, Roe D, Dublin H, Booker F (2018) Wild life, Wild Livelihoods: Involving communities on Sustainable Wildlife Management and Combating illegal Wildlife Trade

Copeland BR, Taylor MS (2009) Trade, tragedy, and the commons. Am Econ Rev 99:725-749

Csardi G, Nepusz T (2006) The igraph software package for complex network research. InterJ Complex Syst 1695:1-9

da Cunha BR, Gonçalves S (2018) Topology, robustness, and structural controllability of the Brazilian Federal Police criminal intelligence network. Appl Netw Sci 3:1-20 https://doi.org/10.1007/s41109-018-0092-1

De Domenico M, Porter MA, Arenas A (2015a) MuxViz: a tool for multilayer analysis and visualization of networks. J Complex Networks 3:159-176

De Domenico M, Solé-Ribalta A, Gómez S, Arenas A (2014) Navigability of interconnected networks under random failures. Proc Natl Acad Sci 111:8351-8356

De Domenico M, Solé-Ribalta A, Omodei E, Gómez S, Arenas A (2015b) Ranking in interconnected multilayer networks reveals versatile nodes. Nat Commun 6:6868

de la Ossa J, de la Ossa-Lacayo A (2011) Cacería de subsistencia en san marcos, sucre, colombia. Revista Colombiana de Ciencia Animal-RECIA:213-224

Drury R (2009) Reducing urban demand for wild animals in Vietnam: examining the potential of wildlife farming as a conservation tool. Conserv Lett 2:263-270

Duffy R, John FAVS, Büscher B, Brockington D (2016) Toward a new understanding of the links between poverty and illegal wildlife hunting. Conserv Biol 30:14-22 https://doi.org/10.1111/cobi.12622 
Duijn PA, Kashirin V, Sloot PM (2014) The relative ineffectiveness of criminal network disruption. Sci Rep 4:4238

Eman K, Meško G, Fields CB (2009) Crimes against the environment: green criminology and research challenges in Slovenia. J Crim Just Secur 11:574-592

Erdös P, Rényi A (1960) On the evolution of random graphs. Publ Math Inst Hung Acad Sci 5:17-60

Fals Borda O (1979) Historia doble de la Costa. Universidad Nacional de Colombia. Banco de la República, El Ancora

García-Díaz P, Ross JV, Woolnough AP, Cassey P (2017) The illegal wildlife trade is a likely source of alien species. Conserv Lett 10:690-698

Gaynor KM, Fiorella K, Gregory GH, Kurz DJ, Seto KL, Withey LS, Brashares JS (2016) War and wildlife: linking armed conflict to conservation. Front Ecol Environ 14:533-542

Gómez S, Díaz-Guilera A, Gómez-Gardeñes J, Pérez-Vicente CJ, Moreno Y, Arenas A (2013) Diffusion dynamics on multiplex networks. Phys Rev Lett 110:028701 https://doi.org/10.1103/PhysRevLett.110.028701

Graif C, Gladfelter AS, Matthews SA (2014) Urban poverty and neighborhood effects on crime: incorporating spatial and network perspectives. Sociol Compass 8:1140-1155 https://doi.org/10.1111/soc4.12199

Granovetter MS (1977) The strength of weak ties. American Journal of Sociology, 78(6), 1360-1380.

Harvey R, Alden C, Wu Y-S (2017) Speculating a fire Sale: options for Chinese authorities in implementing a domestic ivory trade ban. Ecol Econ 141:22-31 https://doi.org/10.1016/j.ecolecon.2017.05.017

Karesh WB, Cook RA, Gilbert M, Newcomb J (2007) Implications of wildlife trade on the movement of avian influenza and other infectious diseases. J Wild Dis 43:S55

Kolby JE, Smith KM, Berger L, Karesh WB, Preston A, Pessier AP, Skerratt LF (2014) First evidence of amphibian chytrid fungus (Batrachochytrium dendrobatidis) and ranavirus in Hong Kong amphibian trade. PLoS One 9:e90750

Lien ME, Law J (2011) 'Emergent aliens': on salmon, nature, and their enactment. Ethnos 76:65-87

Lindsey PA, Balme G, Becker M, Begg C, Bento C, Bocchino C, Dickman A, Diggle RW, Eves H, Henschel P, Lewis D, Marnewick K, Mattheus J, Weldon McNutt J, McRobb R, Midlane N, Milanzi J, Morley R, Murphree M, Opyene V, Phadima J, Purchase G, Rentsch D, Roche C, Shaw J, van der Westhuizen H, Vliet NV, Zisadza-Gandiwa P (2013) The bushmeat trade in African savannas: impacts, drivers, and possible solutions. Biol Conserv 160:80-96 https:// doi.org/10.1016/j.biocon.2012.12.020

Lips KR (2016) Overview of chytrid emergence and impacts on amphibians. Philosophical Trans Royal Soc B: Biol Sci 371: 20150465

Loh J, Harmon D (2005) A global index of biocultural diversity. Ecol Indic 5:231-241 https:/doi.org/10.1016/j.ecolind.2005.02.005

Lotero L, Cardillo A., Hurtado R, Gómez-Gardeñes J (2016) Several Multiplexes in the Same City: The Role of Socioeconomic Differences in Urban Mobility. In: Garas A. (eds) Interconnected Networks. Understanding Complex Systems. Springer, Cham

Magliocca NR, McSweeney K, Sesnie SE, Tellman E, Devine JA, Nielsen EA, Pearson Z, Wrathall DJ (2019) Modeling cocaine traffickers and counterdrug interdiction forces as a complex adaptive system. Proc Natl Acad Sci U S A 116:7784-7792 https://doi.org/10.1073/pnas.1812459116

Mainka SA (2002) Biodiversity, poverty and hunger: where do they meet. Links between biodiversity conservation, livelihoods and food security: the sustainable use of wild species for meat, pp 11-18

Min B, Yi SD, Lee K-M, Goh K-I (2014) Network robustness of multiplex networks with interlayer degree correlations. Phys Rev E 89:042811 https://doi.org/10.1103/PhysRevE.89.042811

Moorhouse TP, Balaskas M, D'Cruze NC, Macdonald DW (2017) Information could reduce consumer demand for exotic pets. Conserv Lett 10:337-345

Morris JA, Whitfield PE (2009) Biology, ecology, control and management of the invasive indo-Pacific lionfish: an updated integrated assessment

Nekaris KAl, Shepherd CR, Starr CR, Nijman V (2010) Exploring cultural drivers for wildlife trade via an ethnoprimatological approach: a case study of slender and slow lorises (Loris and Nycticebus) in south and Southeast Asia. Am J Primatol 72:877-886

Nijman V, Shepherd CR, Sanders KL (2012) Over-exploitation and illegal trade of reptiles in Indonesia. Herpetol J 22:83-89

Niraj SK, Krausman PR, Dayal V (2012) A stakeholder perspective into wildlife policy in India. J Wildl Manag 76:10-18

Oldfield S (2003). The trade in wildlife: regulation for conservation. London Sterling, VA: Earthscan Publications. ISBN 1-85383-959-0,

Patel NG, Rorres C, Joly DO, Brownstein JS, Boston R, Levy MZ, Smith G (2015) Quantitative methods of identifying the key nodes in the illegal wildlife trade network. Proc Natl Acad Sci 112:7948-7953

Phelps J, Biggs D, Webb EL (2016) Tools and terms for understanding illegal wildlife trade. Front Ecol Environ 14:479-489 https://doi.org/10.1002/fee.1325

Pimm SL, Jenkins CN, Abell R, Brooks TM, Gittleman JL, Joppa LN, Raven PH, Roberts CM, Sexton JO (2014) The biodiversity of species and their rates of extinction, distribution, and protection. Science 344:1246752

Pimm SL, Raven P (2000) Biodiversity: extinction by numbers. Nature 403:843

R Core Team (2017) R: a language and environment for statistical computing. R Foundation for statistical computing, Vienna URL https://www.R-project.org/

Rao M, Zaw T, Htun S, Myint T (2011) Hunting for a living: wildlife trade, rural livelihoods and declining wildlife in the Hkakaborazi National Park, North Myanmar. Environ Manag 48:158-167

Ren X-L, Gleinig N, Helbing D, Antulov-Fantulin N (2019) Generalized network dismantling. Proc Natl Acad Sci U S A 116:6554-6559 https://doi.org/10.1073/pnas.1806108116

Roberts N, Everton SF (2011) Strategies for combating dark networks

Robinson JE, Griffiths RA, St. John FAV, Roberts DL (2015) Dynamics of the global trade in live reptiles: shifting trends in production and consequences for sustainability. Biol Conserv 184:42-50 https://doi.org/10.1016/j.biocon.2014.12.019

Rodriguez N, Mancera J, Reyes O (2008) Comercio de fauna silvestre en Colombia. Revista Facultad Nacional de Agronomía Medellín 2(61):4618-4645

Rosen GE, Smith KF (2010) Summarizing the evidence on the international trade in illegal wildlife. EcoHealth 7:24-32

Sageman M (2014) The stagnation in terrorism research. Terrorism and Political Violence 26:565-580 https://doi.org/10.1080/ 09546553.2014.895649

Sánchez A, Asmüssen M, Rodríguez-Clark KM, Rodríguez JP, Jedrzejewski W (2016) Using spatial patterns in illegal wildlife uses to reveal connections between subsistence hunting and trade. Conserv Biol 30:1222-1232 https://doi.org/10.1111/cobi.12744 
Scheffers BR, Oliveira BF, Lamb I, Edwards DP (2019) Global wildlife trade across the tree of life. Science 366:71-76 https://doi. org/10.1126/science.aav5327

Smith KM, Anthony SJ, Switzer WM, Epstein JH, Seimon T, Jia H, Sanchez MD, Huynh TT, Galland GG, Shapiro SE (2012) Zoonotic viruses associated with illegally imported wildlife products. PLoS One 7:e29505

Toth N, Gulyás L, Legendi RO, Duijn P, Sloot PM, Kampis G (2013) The importance of centralities in dark network value chains. Eur Physical J Special Topics 222:1413-1439

Wandelt S, Sun X, Feng D, Zanin M, Havlin S (2018) A comparative analysis of approaches to network-dismantling. Sci Rep 8: $13513 \mathrm{https}: / / \mathrm{doi} .0 \mathrm{rg} / 10.1038 / \mathrm{s} 41598-018-31902-8$

Wyatt T (2013) The security implications of the illegal wildlife trade. J Soc Criminol:130-158

Zimmerman ME (2003) The black market for wildlife: combating transnational organized crime in the illegal wildlife trade. Vand J Transnat'l L 36:1657

Publisher's Note

Springer Nature remains neutral with regard to jurisdictional claims in published maps and institutional affiliations.

Submit your manuscript to a SpringerOpen ${ }^{\odot}$ journal and benefit from:

- Convenient online submission

- Rigorous peer review

- Open access: articles freely available online

High visibility within the field

- Retaining the copyright to your article

Submit your next manuscript at $\boldsymbol{\nabla}$ springeropen.com 